\title{
INTEGRATED PHOTOGRAMMETRIC SURVEY AND BIM MODELLING FOR THE PROTECTION OF SCHOOL HERITAGE, APPLICATIONS ON A CASE STUDY
}

\author{
C. Palestini ${ }^{1 *}$, A. Basso ${ }^{1}$ L. Graziani ${ }^{2}$, \\ ${ }^{1}$ Dipartimento di Architettura, Università degli Studi “G. d'Annunzio” Pescara, viale Pindaro 42, 65127 Italia, \\ caterinapalestini@libero.it - alessandro.basso77@gmail.com \\ ${ }^{2}$ Department of Construction, Civil Engineering and Architecture (DICEA), Università Politecnica delle Marche, via Brecce \\ Bianche, 60131 Ancona, Italy - lorenzo_graziani@ virgilio.it
}

\author{
Commission II, WG II/8
}

KEY WORDS: Photo-modelling, HBIM, Knowledge modelling, Survey of historical building

\begin{abstract}
:
The contribution, considering the use of low-cost photogrammetric detection methodologies and the use of asset Historical-BIM, has as its aim the theme of knowledge and the adaptation of safety in school buildings, a topic brought to attention by the many situations of seismic risk that have interested the central Apennines in Italy. The specific investigation is referred to the Abruzzo region, hit by the recent earthquakes of 2016 and 2009 that have highlighted the vulnerability of the building structures involved in a large seis mic crater covering large areas of the territory. The need to consider in advance the performance standards of building components, especially concerning the strategic ways of the functions contained in them, starts here. In this sense, the school buildings have emerged among the types on which to pay attention, a study theme to be promptly considered, considering the functions performed within them and the possible criticality of such constructions, often dated, enlarged or readjusted without appropriate seismic adaptation plans. From here derives the purpose of the research that is directed towards a systematic recognition of the scholastic heritage, deriving from objective and rapid surveys at low cost, taking into consideration the as-built and the different formal and structural aspects that define the architectural organisms to analyse and manage through three-dimensional models that can be interrogated using HBIM connected to databases containing information of a structural and functional nature. In summary, through the implementation of information in the BIM model, it will be possible to query and obtain in real time all the necessary information to optimize, in terms of efficiency, costs, and future maintenance operations.
\end{abstract}

\section{INTRODUCTION}

Dealing with the restoration of ancient buildings, a deep knowledge of the artefact is fundamental, and the major part of information about the past is $2 \mathrm{D}$-based and paper-based. Thus, collecting information is often time consuming and barely efficient.

In addition, collecting all necessary data is a difficult operation and the risk to lose some important information is real.

Building Information Modelling (BIM) and Historical Building Information Modelling (HBIM) may represent the solution (Logothetis, 2015), allowing the integration of many types of information from the construction of the building to date, of each element that compose the entire artefact, in a unique database (Biagini, 2016).

In this way, the user is able to query all the needed information with one click on each element defined in the BIM model (Napolitano, 2018).

The definition of a complete HBIM concerns the need of a very detailed model, with a deeper level of detail (LOD) than BIM of modern construction, and this implies the definition of customized object libraries.

The aim of this article is to apply the innovative approach to the construction management of historical building interventions, based on BIM technologies (Barazzetti, 2015; Inzerillo, 2016; Oreni, 2017; Soler, 2017; Bruno, 2018).

The goal of the work is to create a digital model that provides the greatest amount of fundamental information for any future maintenance work or renovation project, allowing all updates to be made in progress.

The "Tito Acerbo" technical institute is still today the oldest and

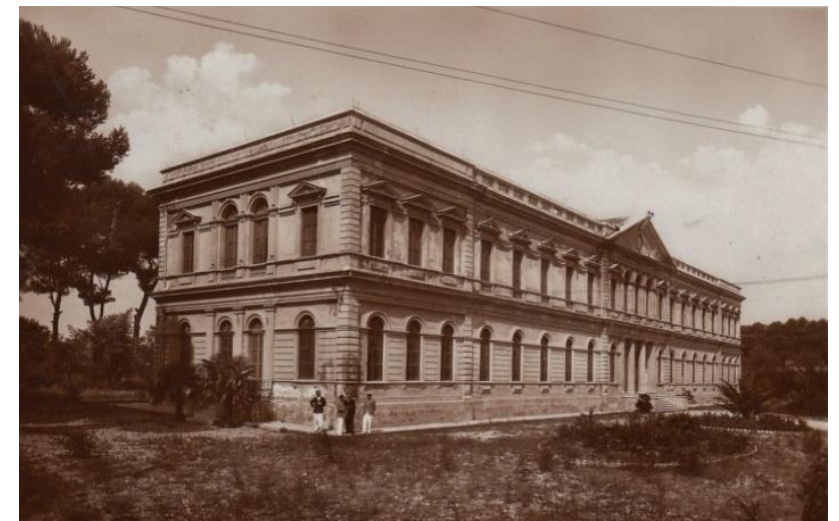

Figure 1 Tito Acerbo photo of 1931.

most representative school building in Pescara (Figure 1). This building was originally a boarding school, built at the end of the nineteenth century in line with technical standards of the era, issued to ensure the sanitary and distributive conditions of the environments dedicated to teaching, to the correct sizing of the classrooms, the formal structure, the correct sunshine in relation to the areas, and in the services. It has neo-classical forms distinguished by a pronaos crowned by a tympanum that introduces the central vestibule, emphasizing the entrance to the building. The main façade is articulated horizontally by a stringcourse that divides it into two parts characterized by a sequence of linear windows with triangular tympanums on the upper floors and round arches on the ground floor. The planimetric system reflects the scheme of the façade based on an axis of 
symmetry with atrium and staircase placed frontally to the entrance from which the side blocks are inserted with the corridors leading into the classrooms.

In the evolutionary stages of the building, many changes were made and they are inherent to the original plant. The first remakes, dating back to the fifties, concern the parts damaged by the bombing of 1943 , including the southern portion. In 1972, the south side arm was built to implement the didactic spaces, and this addition modified the initial symmetry. In addition to minor maintenance and punctuation of the façade carried out in the 1990s, consolidation actions were started in 2009 following the earthquake that devastated L'Aquila. In that time, structural improvement according to the current antiseismic regulations was carried out. In detail, local interventions were carried out regarding the stiffening of the floors on the first floor, consolidation of the walls and improvement of the seismic joint located in the stretch where the south-west wing meets the main body.

\section{METHODS}

\subsection{The Integrated Survey}

By entering into the debate on strategies to be followed for the implementation of digital models in the field that are not only formal, but then specifically operational in relation to their use in the design of detection interventions aimed at improving, managing and adapting the security of existing spaces, application systems have been used based on innovative technological procedures that have significantly modified the executive workflow (Amadesi, 1978; Cundari, 1984; De Luca, 2011). An example of this is the survey carried out in the case study of the "Tito Acerbo" technical institute in Pescara, the subject of the Erasmus project KA201-024091, organized by integrating the use of terrestrial photo-modelling assisted by Unmanned-Aerial-Vehicle (UAAV) systems.

The integrated survey and its restitution obtained through automated modelling techniques deriving from Image-Based systems, together with manual $3 \mathrm{~d}$ methodologies, mainly polygonal, based on two-dimensional photo-planes, have allowed to calculate the overall appearance and the modular layout of the different decorative elements (taken from the main macro segments). Three-dimensional references, acquired from the self-modelling phase by point cloud, have provided an excellent basis, useful to have a detailed, proportionate and topologically correct reconfiguration of the decorative apparatus of the artefact inside the parametric workspace. The extrapolation of numerous acquired data of the existing building, through the described workflow, was directed to the achievement of a three-dimensional model of the school, compatible with BIM.

The latter, allowing the insertion on an interactive platform, is an excellent solution to instruct a cross-examination network useful for carrying out checks on different aspects and issues concerning the school structure.

The site inspection, fundamental for the start of the detection phases, allowed to program the sequence of operations related to the different methods used (Palestini, 2017). Specifically, the presence of a large square, in the perimeter and front spaces, allowed to manage the sequence of shots on the ground, and the aerial manoeuvres performed with drone, ensuring sufficient depth of field adequate to obtain a good overlap of the frames, which gave rise to the necessary points for image based detection and for photo-modelling.

The survey project was also supported by cadastral information, by the historical documentation provided by the institute, and by the $\mathrm{CAD}$ plans derived from previous surveying operations.

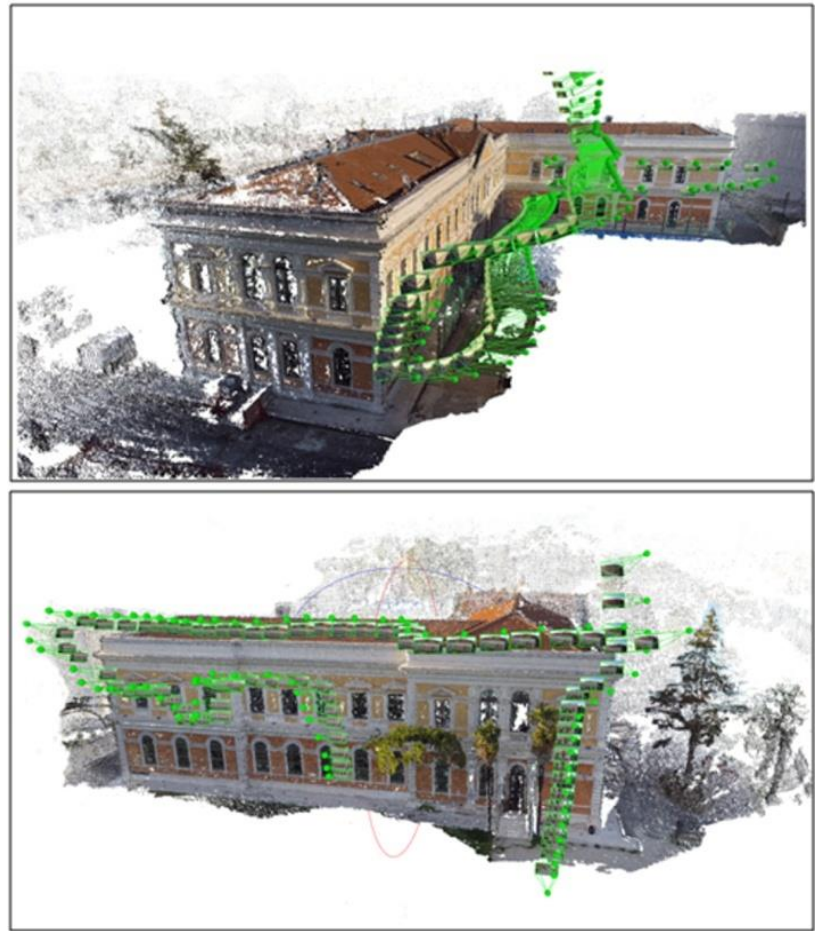

Figure 2 Point clouds from drone elaborated with the Pix $4 d$ software.

These data were useful not only in the 3D detection and redesign phase, but above all, in the stratigraphic digitization interventions of the HBIM data specifically described in section 2.2 .

The survey of the building was then designed and conducted with the help of some well-known software such as Agisoft Photoscan, Recap Photo and Pix4d, specific in the management of three-dimensional photogrammetric algorithms (Figure 2). Taking advantage of the photographic data, organized in multiple shooting sessions performed with similar conditions of diffused lighting, it was operated in part through shots taken from the ground, resulting from the use of digital cameras with variable lenses between $30^{\circ}$ and $135^{\circ}$, partly using two different types of drone. In particular, the Yuneec Chroma drone equipped with a GoPro and the S1000 model of the DJI house, equipped with Canon with integrated stabilizer were used. They recorded videos, from which the full HD frames were derived, obtaining a very detailed description of the highest and physically inaccessible parts of the building. The use of systems that operate with photography, with the use of common cameras; using passive sensors and precisely exploiting the light present in the environment for the acquisition of the images to be processed, has the advantage of not requiring the use of more expensive equipment such as metric camera or the $3 \mathrm{~d}$ scanner.

From the simple photographic images it was possible to obtain a detailed three-dimensional model that respects the modules and the proportions together with the chromatic information of the building's external materials (Figure 3). The obtained 3D model, used as point clouds or triangulated meshes, guides the next three-dimensional redesign on a parametric management modelling platform. This generates a fast system to create polygonal assets that can be implemented within procedural schedules used in the HBIM system, for example, as decorative elements and architectural orders, present in the building, of in four main steps based on the basics of calculation of the Structure from Motion algorithm (SfM). The first, after placing the photo-data in the computer, consists of the alignment of the 
particular formal complexity ${ }^{1}$. The procedure processes the data different shots of the camera: in this phase the software analyzes all the photos searching for the corresponding points in relation to the chromatic peculiarity and the luminous factor: for each image the orientation of the camera and the related calibration parameters are identified, from which the lens distortion coefficient is also obtained.

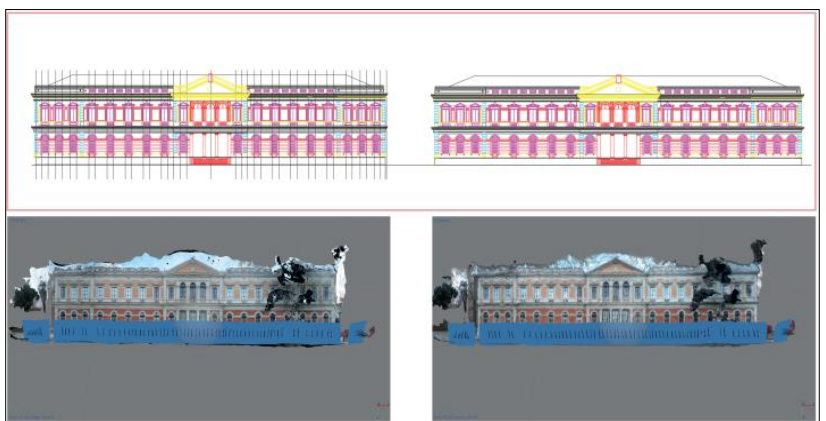

Figure 3 Analysis of the main facade modules based on photoplane from Photoscan.

From this elaboration, a "Point Cloud Based" is generated, through an automatic collimation that is a cloud of "sparse" points constituted by the "Key points" necessary to inquire, in a cartesian coordinate system, the spatial model of the detected objects showing in three-dimensional environment the exact layout of each photo shoot. In the second phase of the workflow, there is a more thick "Dense Point Cloud" obtained on the basis of the positioning of the interpolated points, from which the program extracts the information related to the colour and the plastic detail of the objects. The Dense Point Cloud can be modified, cut and optimized according to the next phase. The third step, in fact, consists in the mesh construction: the algorithm provides to "cover" the points with a network of triangles to form a mesh surface called TIN, or "Triangulated Irregular Network", considering each point of the cloud as a vertex of a contiguous and irregular triangular polygon with a Z coordinate, transforming the point cloud into a polygonal model. It is useful to clarify that, unlike the Laser Scanner, which returns an "ordered" cloud of points obtained from a scanning step formed by rows and columns, Image Based systems create a network of very dense, but "disordered" points, producing irregular polygonal meshes, configured according to a logic of calculation produced by the data and photographic information entered. It may therefore be necessary to intervene

\footnotetext{
${ }^{1}$ The insertion on a parametric management platform of $3 \mathrm{~d}$ assets, the result of self photogrammetric modeling, necessarily requires a further phase of mesh retopology. The elements generated by Image based algorithms, in fact, return an internal triangular geometry that is not organically distributed in relation to the actual shape of the reconfigured object. This automat procedure, based on that density of the point cloud, easily implies an excess of vertices and polygonal faces that aggravates the hardware calculation and makes it impossible to manage the polygonal mesh in software such as Revit or Archicad, to the extent that cloned as instances and used as semantic elements within procedural groups and subgroups. The solution is to remodel complex elements by means of authoretopology and sculpting functions, within specific software such as Z-brush or 3D-Coat, modifying the distribution conformation of network meshes through semi-automated methodologies. These functions aim at obtaining a more orderly management of the polygonal mesh in quod, polygons with four vertices, taking into account the flat areas, the jutting or convex elements, or more generally the more articulated plastic parts. The $3 \mathrm{~d}$ element, Thanks to retopology, it will be exported and reimported with ease on the BIM platform to be finalized within the software in the families of interactive and procedural schedules.
}

on the polygonal density based on the desired visual quality but also in relation to the required survey scale. In this phase, it is very often possible to incur in artifacts or errors in definition often due to the so-called digital noise, such as vegetation, which tends to cover part of the structure in photographic shooting, generating gaps and imperfections that make the model unsuitable for the next phase of texturing. It may therefore be necessary to make some corrections, decreasing the polygon density of the meshes, removing unnecessary components of disturbance, accidentally calculated as present in the frames, or closing gaps often identifying excessively concave parts or inaccessible points of the detected artefact.

However, the program allows, for further operations, the exportation of point clouds and meshes to alternative external editing software. Following the creation of the meshes, the fourth and last phase follows the acquisition of the texture applied on the geometric model, carried out by means of an orthographic projection using UV map of the colour data deriving from the photos previously used for the threedimensional photogrammetry operations (Figure 4). A diffuse map and a normal map are then generated, necessary for the detailed and photorealistic rendering of the $3 \mathrm{~d}$ model obtained, which can be exported and implemented on external precalculated or real-time rendering (R.T.R.) platforms. Specifically, in the case study the alignment phase of the shots immediately provided an excellent result, returning a cloud of scattered points provided with RGB data taken from the photographs themselves.

In order to manage the highly detailed cloud of points in a more fluid way, streamlining the hardware calculation of the data, we opted for a preliminary decomposition in "chunks", set according to the different sections of the building. To allow the precise blending of the single clouds, before performing the mesh calculation, a precautionary operation was performed to identify precise visible marker points, positioned in specific areas of the main facades, through which it was possible to reconnect the sessions together of photogrammetric survey.

The operation of joining chunk, prior to the calculation of the mesh, turns out to be more precise because the software, working on photogrammetric data contained directly in the point cloud, accurately determines each marker identified by the homologous points of a pair of photos. This operation, if carried out in the following phase, in which the program has already processed a continuous three-dimensional surface, could generate polygonal interpolation errors in correspondence with the model, due to a different topology generated automatically during the "meshing" phase of the acquired points clouds in different sessions. The survey of the school building was therefore managed through 4 sessions-chunks, each relating to a façade of the building, subsequently merged. Chunks were finally arranged to merge everything into a single editable model, in the meshing phase. The effectiveness of this detection methodology is given by the low cost of the equipment used and by the speed of execution that facilitate the fact-finding investigations. Among the advantages of the system, it is important to underline the significant non-invasiveness in the case of historic buildings such as the one in question, which allowed the acquisition of fundamental data for the modelling and transfer phases on virtual BIM platforms.

In addition, the survey was verified with the acquisition of external calibration points, detected with total station (Topcon GPT3005) to perform checks and also checks on the error margins found on the cloud of points, as well as to fix in an unmovable Marker points. Likewise, for internal spaces, the data acquisitions with total station have been integrated with the Image based photogrammetric system, used specifically for the 
survey of the most complex and articulated environments such as the central staircase.

The survey through the total station also allowed to connect the survey of the interior with the point cloud generated by photogrammetric processing from a drone. In particular, a station has been made outside, in front of the main entrance from which the side vertexes of the façade and some detail points of the entrance portal have been collimated. This station was then connected to an internal station (located in the atrium in front of the internal staircase) from which some detail points of the staircase were collimated.

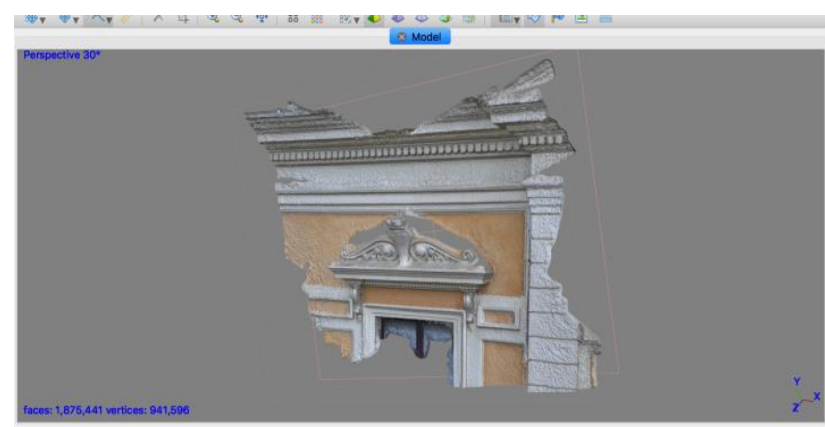

Figure 4 Decorative detail of a large window, by Photoscan photo-modelling. Reference for digital redrawing.

In this way, it was possible to synchronize the survey of the points of the internal points with the points collimated to the outside and being the latter also belonging to the point cloud, it was possible to hook the interior survey to the point cloud of the outer envelope. The set of internal survey and point cloud was used as the basis for modelling the HBIM Model elements. Unlike a $3 \mathrm{~d}$ model obtained from a cloud of points, which serves inside it articulated information related to the geometry of the detected volume, the geometric model created through BIM system, although schematic and less detailed, as well as allowing a reading of the geometry and data metric, possesses the prerogative to host and manage within it a complex database that include physical, mechanical and technical relationships of the composing elements and materials, such as parameters weight, thickness or structural calculations, as well as user-defined parameters, implementable over time and useful in any planning or restoration. Thus, the integration between the BIM system and Image Based survey offers a model developed on a direct volumetric and proportional reference point cloud, as well as a questionable and parametric data-base concert, made up of data families containing criteria already defined or to be defined (Figure 5).

\subsection{The use of HBIM platform.}

In this paper, BIM approach was preferred over CAD or GIS because of three main factors:

- the possibility to have a complete virtual model of the building;

- the possibility to implement non-geometrical aspects such as materials, dating, or construction features directly into the 3D model;

- the possibility to simulate the consequences of a particular design decision, reducing the steps needed to achieve the final result.

The digital model could be continuously updated, following the life cycle of the building. In the HBIM panorama, the creation of an interoperable model useful for different operators (engineers, architects, restorers, tourists, etc.) is fundamental. Thus, information about history, materials, construction phases, technological aspects, and previous intervention were implemented inside HBIM.

HBIM of the school was defined by taking into account its use (school), age (existing as historical building) and ownership (public). A historical research was carried out to understand the different construction stages, which were represented in the final HBIM with multi-temporal elements. The geometry of the element and other acquired data were interconnected to reach an accurate Level of Detail (LoD) of HBIM, as defined in the UNI11337-4. The survey and the geometrical data allow to define the model with a Level of Graphical details (LoG) equal to $G$ that indicates a complete definition of the elements with information capable to generate rendering. The acquired information about materials, structural functions, age of construction, and interventions on the elements allowed to define a Level of Information (LoI) equal to L350, indeed it includes model detail, and elements that represent how building elements interface with various systems and other building elements with graphics and written definitions. To reach a LoG equal to $G$, the point cloud with mesh-based algorithms is insufficient because each elements must be defined according to BIM technology. To solve this problem, 3D model was redesigned into BIM software (Graphisoft ArchiCAD v21 EDU) following these phases:

- import of point cloud into ArchiCAD;

- definition of simple shapes using native tools of BIM software;

- definition of complex shapes (vaults, windows, stairs, etc...) based on partial point-cloud interpolation.

- overlapping of the point-cloud with the ArchiCAD tools (Figure 8);

- connection of each element with its semantic data (for instance time of construction, structural remediation, typology, etc...).

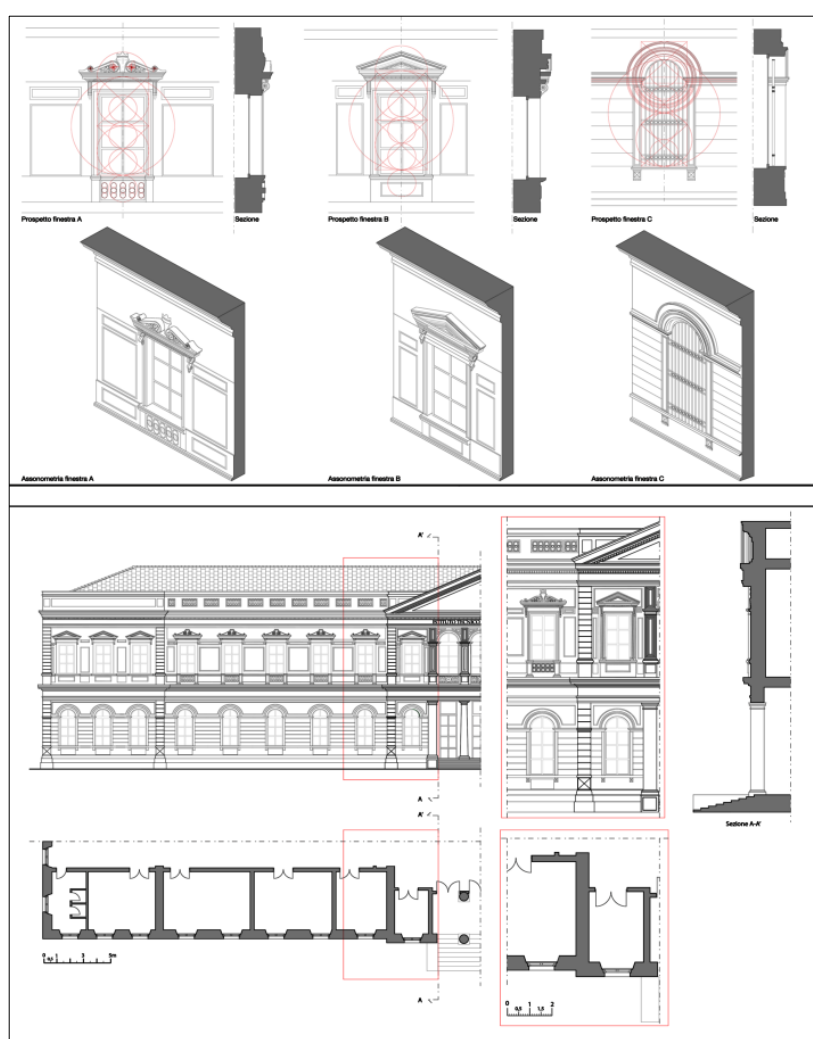

Figure 5 Windows' abacus, synthesis of proportional and modular study of the decorative system. Front elevation and sections. 
The 3D modelling of the exterior of the building (façades, decorations, and roof) was carried out by overlapping the point cloud from the survey with the parametric object in ArchiCAD library. During the designing process, the element were positioned so that the deviation standard between $\mathrm{x}, \mathrm{y}, \mathrm{z}$ coordinates of the point cloud and the surface of the elements was minimum.

Figure 6 shows some BIM objects used in the project: walls, vaults, stairs, ceilings, columns, and windows. All the elements were designed by using the native ArchiCAD tools, except for decorations that were mesh-modelled with external 3D software

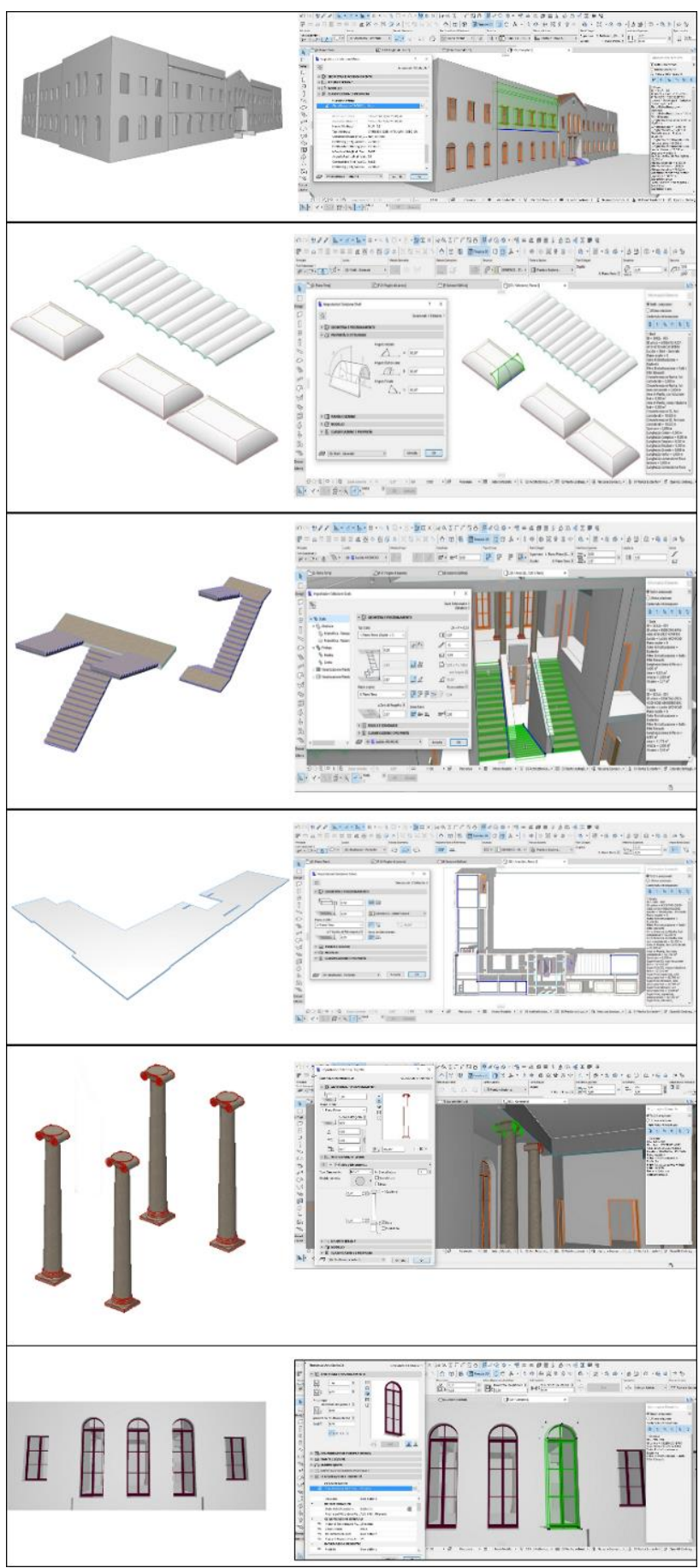

Figure 6 The final BIM is made up of a combinations of objects with variable geometric complexity.

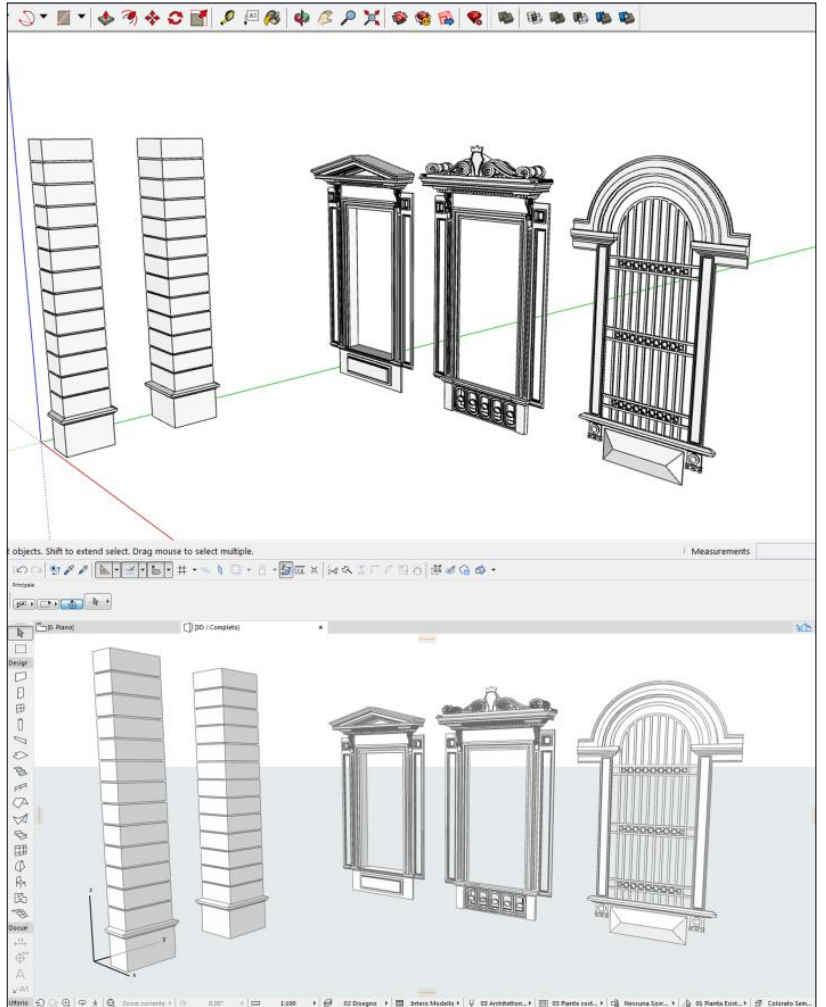

Figure 7 Customized 3D elements in SketchUP software (top), and in ArchiCAD. (bottom)

(SketchUP Make 2018) and then imported inside ArchiCAD (Figure 7).We chose SketchUP because of its speed-modelling capability, and its direct compatibility with ArchiCAD.

Though ArchiCAD is able to model organic shapes by the morph tool, we chose to generate plaster decoration externally by using mesh-based software to have a faster workflow.

No NURBS operators were used to generate 3D elements because BIM environments is sufficient to generate a model with good accuracy (Quattrini, 2015).

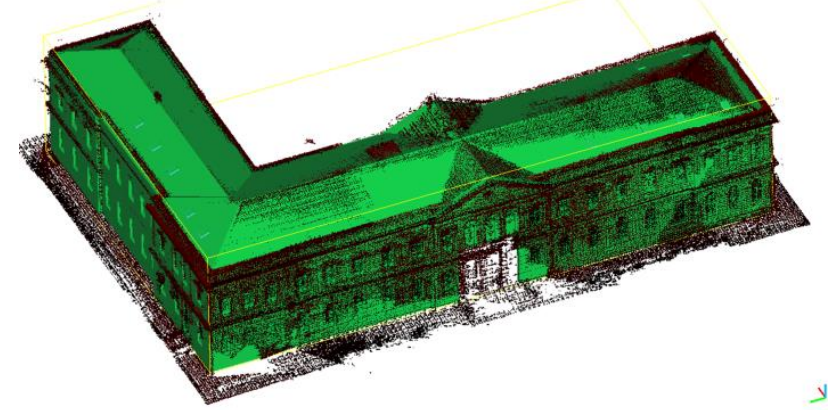

Figure 8 Overlapping of point-cloud (red) with elements designed in ArchiCAD. (green)

The elements with structural function were defined according to their structural function (wall, beam, column, etc...), and their past intervention (year and type of restoration).

In order to clearly define the construction techniques of structural elements, a database with short code was associated to a description of the structure (Table 1), and a unique colour was associated to each of them.

In this way, ArchiCAD can provide a visualization of the changes and modifications occurred in the past, till the current shape. 
In addition, IFC-related controls were inserted in each structural element, allowing the direct export-import inside software for structural analysis.

Since the building was maintained in 2017 (after earthquake in Abruzzo in 2009), all the interventions were inserted in the model (Figure 12).

In detail, the structural intervention regards:

- $\quad$ Fabric-Reinforced-Cementitious-Matrix(FRCM) plaster on some walls of the main building;

- insertion of a seismic joint between south wing and main building with scuci-cuci of the adjacent walls;

- circular-confining of the columns in the entrance and in the first floor with Carbon-Fiber-ReinforcedPolymer (CFRP);

- insertion of a L-steel curb on the perimeter of the ceiling.

Thus, the model contains two groups of information: a first general level of information about stage of construction and global intervention, and a second level of information containing a detailed description of the last structural improvement.

\begin{tabular}{|c|c|c|c|}
\hline Elements & $\begin{array}{l}\text { Construction } \\
\text { technique ID }\end{array}$ & Color & Description \\
\hline \multirow[t]{2}{*}{ WALLS } & $\mathrm{B}$ & & Brick wall \\
\hline & $S \& B$ & & $\begin{array}{l}\text { Core and veneer } \\
\text { wall }\end{array}$ \\
\hline \multirow[t]{8}{*}{ CEILINGS } & $\mathrm{CH}$ & & $\begin{array}{l}\text { Reinforced concrete } \\
\text { and hollow blocks } \\
\text { mixed floor }\end{array}$ \\
\hline & $\mathrm{C}$ & & $\begin{array}{l}\text { Reinforced concrete } \\
\text { floor }\end{array}$ \\
\hline & VBC & & $\begin{array}{l}\text { Vaulted brick } \\
\text { ceiling }\end{array}$ \\
\hline & I & & I-beam $120 \mathrm{~mm}$ \\
\hline & NP & & NP-beam 200mm \\
\hline & REP & & $\begin{array}{l}\text { REP beam with } \\
\text { hollow blocks } \\
\text { mixed floor }\end{array}$ \\
\hline & $\mathrm{V}$ & & $\begin{array}{l}\text { Ceilings with } \\
\text { semicircular vaults }\end{array}$ \\
\hline & $\mathrm{CV}$ & & $\begin{array}{l}\text { Ceilings with coved } \\
\text { vaults }\end{array}$ \\
\hline ROOF & $\mathrm{PH}$ & & $\begin{array}{l}\text { Prefabricated } \\
\text { concrete beam and } \\
\text { hollow blocks } \\
\text { mixed floor } \\
\text { HEA-beam 200mm } \\
\text { with HI-BOND }\end{array}$ \\
\hline & M & & $\begin{array}{l}\text { A55/P } 600 \\
\text { corrugated iron } \\
\text { sheet }\end{array}$ \\
\hline
\end{tabular}

Table 1 Database with information about construction techniques

\section{RESULTS}

\subsection{Accuracy of the HBIM}

The geometric accuracy of 3D HBIM of Tito Acerbo was performed by comparing the point cloud from the survey with the model of the school from ArchiCAD with the open source software CloudCompare, using the point clouds as reference. The software is able to compare the point cloud (format file .e57) and the model exported from ArchiCAD (format file .obj), and to generate statistics about the displacement between points in the cloud and meshes in the model.

Before the test, the point cloud was validated by comparing the position of some points with their coordinates measured by total station. Displacement between the coordinates of point clouds, and coordinates from total station was about $2 \mathrm{~mm}$ on the length of the main façade (long about $66 \mathrm{~m}$ ), demonstrating a very good accuracy of the point cloud.

Distance between point cloud and mesh from HBIM was compared, and the model was practically overlapped to point cloud.Figure 9 shows the results of computation with statistical information. In detail, the comparison between HBIM and point cloud shows an histogram with a peak on zero meaning that HBIM had a very good accuracy if compared to point cloud. In detail, a percentage minor than $46 \%$ has a distance of about $4 \mathrm{~cm}$.

The points with the major deviation were located at the base of the building because in this places the 3D model has no points, while point cloud presents many points calculated by photogrammetry. A better accuracy of the 3D model can be obtained by excluding these regions from computation.

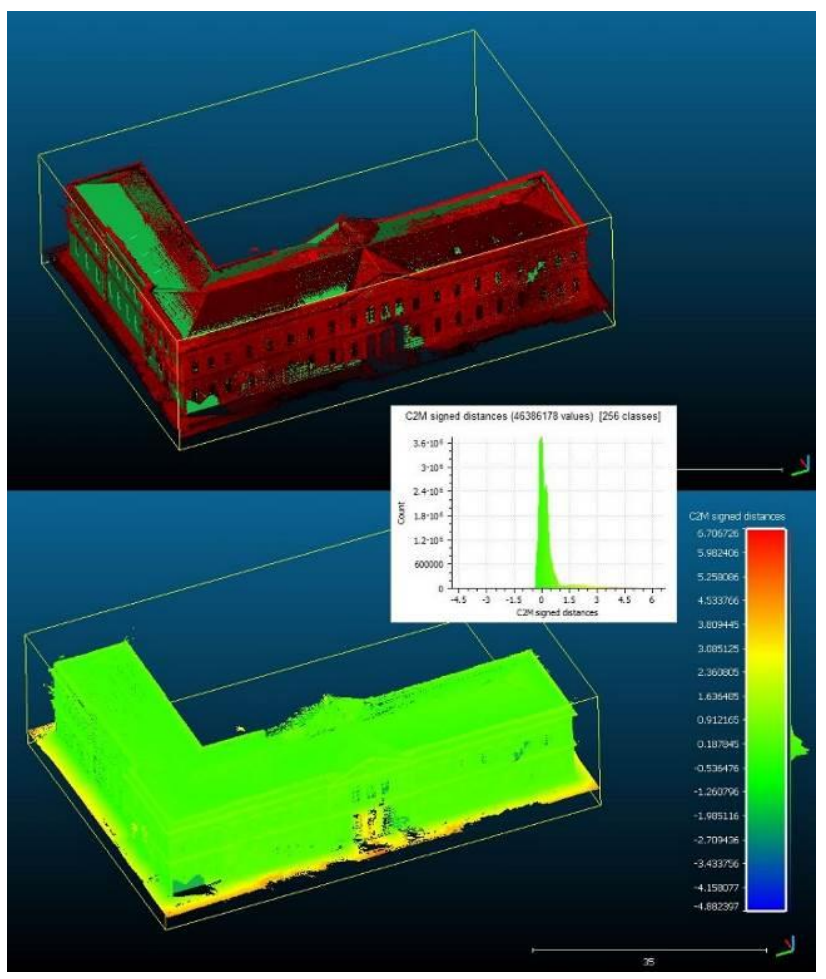

Figure 9 Accuracy of HBIM evaluated by CloudCompare software. Top) Point cloud (red) was overlapped to HBIM (green). Bottom) scalar field from cloud to mesh distance computation.

\subsection{HBIM of Tito Acerbo}

After the connection between database and 3D model, the elements with common properties in the database was highlighted with ArchiCAD, allowing to distinguish the elements build at the same time, or elements build with the same techniques. Thus, many types of thematic tables can be exported from the software.

Figure 10 shows the different construction stages, and it allows an immediate evaluation of the modifications occurred, which are fundamental to understand the different connections between the elements of the school. 


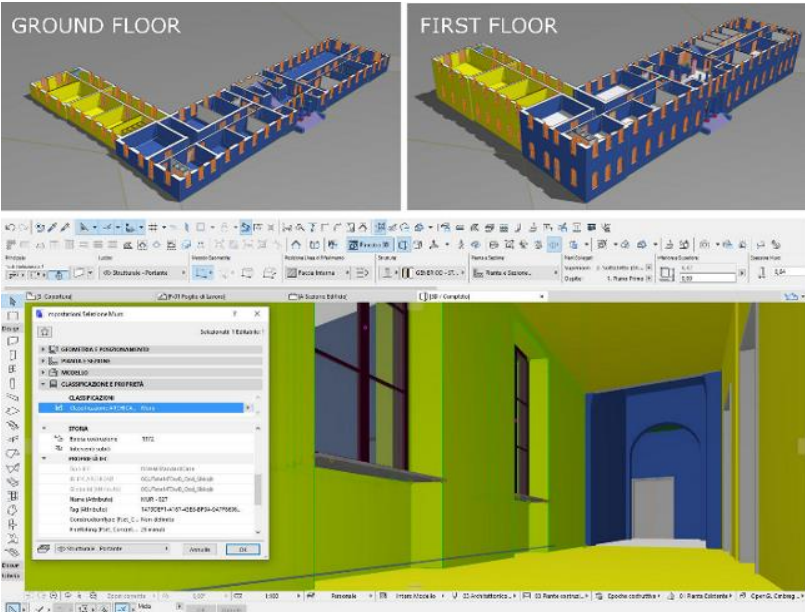

Figure 10 Highlight of construction stages in ArchiCAD from a global point of view (top), and from an immersive view (bottom).

Thanks to BIM, thematic tables can be 2D designs, axonometric views or immersive environments with different colours depending on the age of construction (see Figure 10).

Another important result from BIM is the diversification of the model depending on the construction technology. Figure 11 shows varicoloured structural elements depending on their construction techniques.

By clicking on the model, an operator can deduce all the needed information for each element. For example, a click on a wall allows to obtain information about: year of construction, construction technique with its extended description.

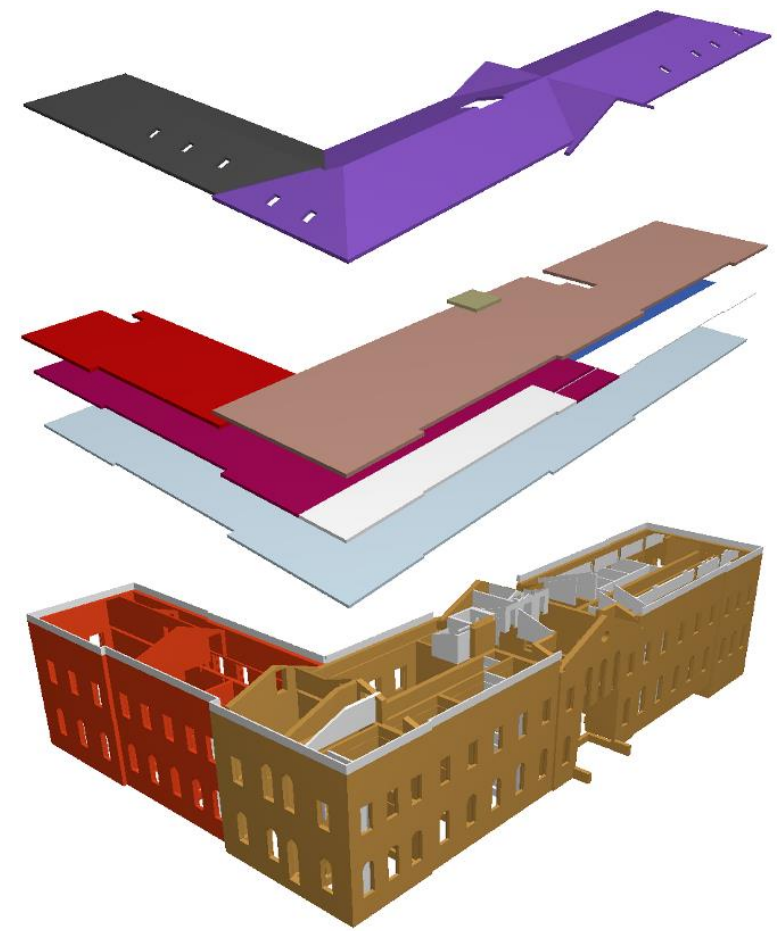

Figure 11 Highlight of construction techniques in ArchiCAD of walls, ceiling, and roof. Colours defined in Table 1.

In detail, Figure 11 shows that the walls of the main building were core and veneer walls $(\mathrm{S} \& \mathrm{~B})$, while the south wing was built using brick walls (B). The structure of the ceiling varies depending on the floor and their position. Only the ceiling of the ground floor has the same characteristics (reinforced concreteC) for all its extension.

Figure 12 shows the elements that were affected by the last structural renovation.

Different thematic models can be overlapped to obtain a combination of many crossed information to compare.

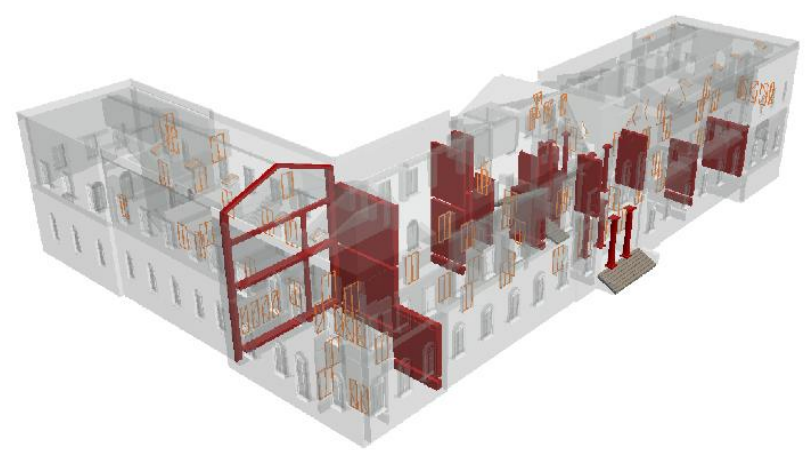

Figure 12 Structural intervention implemented in 2017, after Abruzzo earthquake. The elements that were affected by the last structural renovation.

\section{MULTI-USE OF HBIM}

First of all, the HBIM of Tito Acerbo will allows to optimize future maintenance of the building in terms of type of restoration and money.

Thanks to BIM technology all the future information can be inserted into the model, allowing to obtain a ever updated digital model of Tito Acerbo, that can change as reality changes. Also, further structural or non-structural interventions could be implemented into the created model to generate an alwaysupdated HBIM of Tito Acerbo school.

The interactive management of the elements, through the capability of visualizing endless views from the internal database, gives the opportunity to virtually "compose and decompose" the building as the operator desire.

The HBIM from this paper could be integrated with mechanical, electrical, and plumbing (MEP) in order to optimize maintenance of plants.

Thank to the ability of BIM technology to generate tables and databases based on a specific information, it will be the possibility to generate an interactive abacus of the classroom to better plan their utilization for educational purposes (students' disposition or Hi-Tech installation).

Another application of the model could be the optimization of escape routes in terms of safety.

Finally, thanks to the direct connection between ArchiCAD and BIMx (a software for the navigation and interrogation of BIM model on mobile platforms), it was possible to export the HBIM model of the school, and navigate it on a smartphone or tablet in an immersive way.

\section{CONCLUSIONS}

The adherence to the BIM and HBIM information systems now offers the possibility of linking a three-dimensional model to a complex data network, providing the opportunity to draw on heterogeneous families of information related to different time periods. Such intervention methodologies applied to historic buildings are not however exempt from the problems related to the integrated use of dissimilar digital formats and interoperability between the different programs involved: the adhesion to software for the design of contemporary buildings, such as ArchiCAD and Revit, rather than to programs aimed at 
recovering the existing built heritage, does not take into account the irregularities and typological design variations that characterize the historical contexts. The historical building is not compatible with the automatic functionality of parametric software and with their modelling systems oriented to the definition of regular shapes and geometries based on seriality, on the homogeneity of proportions and on the repetition of instances. The case study shows that the involvement in the executive pipeline of specific programs for image-based surveying and for the polygonal modelling, necessary for the correct insertion of three-dimensional reference within the work space and for the constitution of the procedural schedules, has substantially the management of a fluid workflow within a single software made more complex, making it even more difficult to control the error on every single element decomposed semantically and then used in the information system. Innovative, instead, is the use of HBIM as a tool for controlling the artefact in relation to the timeline: the display of interrogable semantic models provides information that can always be implemented on the management of the asset, in relation to the past, with regard to historical memory, but above all to the future, as a resource for planning maintenance and documentation programs for ordinary and extraordinary operations. While BIM helps to coordinate the various professional figures in the construction phases of a building in a circular system, intervening with a graphical-digital synthesis of the skills and the numerous actors involved in the building process, HBIM focuses on the survey, definition of the conservation status of places and materials, in order to plan informed measures on the building. In summary, the HBIM process is a resource for all subsequent monitoring activities on the architectural product. The current change in the construction sector, already started by the introduction of BIM, seems to involve, with the use of HBIM, also sectors that deal specifically with the protection of the existing heritage and more generally of the architectural and archaeological restoration, with positive consequences on the economy and on the increase of the quality of the interventions, possible in terms of productivity and development.

\section{ACKNOWLEDGEMENTS}

The authors wish to thank in particular the people involved in the acquisition and management of data and in the project on site among which the architect Matteo Spinozzi for the shootings on drone.

\section{REFERENCES}

Amadesi, E., 1978. Fotointerpretazione e aerofotogrammetria. Bologna, Italia: Pitagora Edizioni.

Barazzetti, L.; Banfi, F.; Brumana, R.; Oreni, D.; Previtali, M.; Roncoroni, F., 2015. HBIM and augmented information: towards a wider user community of image and range-based reconstructions, In: The International Archives of the Photogrammetry, Remote Sensing and Spatial Information Sciences - ISPRS Archives, Vol. XL-5/W7, 35-42.

Biagini, C., Capone, P., Donato, V., Facchini, N., 2016. Towards the BIM implementation for historical building restoration sites, Automation in Construction, 71, 74-86.

Bruno, S., De Fino, M., Fatiguso, F., 2018. Historic Building Information Modelling: performance assessment for diagnosis- aided information modelling and management, Automation in Construction, 86, 256-276.

Cundari, C., 1984. Fotogrammetria architettonica. Roma, Italia: Edizioni Kappa.

Inzerillo, L., Lo Turco, M., Parrinello, S., Santagati, C., Valenti, G.M., 2016. BIM and architectural heritage: towards an operational methodology for the knowledge and the management of Cultural Heritage, DISEGNARECON, 9/n16, 19.

Logothetis, S., Delinasiou, A., Stylianidis, E., 2015. Building information modelling for Chultural Heritage: a review, In: ISPRS Annals of the Photogrammetry, Remote Sensing and Spatial Information Sciences, II-5/W3, 177-183.

De Luca, L., 2011. La fotomodellazione architettonica: rilievo, modellazione, rappresentazione di edifici a partire da fotografie. Palermo, Italia: Dario Flaccovio Editore.

Napolitano, R.K., Scherer, G. and Glisic, B., 2018. Virtual tours and informational modeling for conservation of cultural heritage sites, Journal of Cultural Heritage, 29, 123-129.

Oreni, D., Brumana, R., Della Torre, S., Banfi, F., 2017. Survey, HBIM and conservation plan of a monumental building damaged by earthquake, In: The International Archives of the Photogrammetry, Remote Sensing and Spatial Information Sciences, XLII-5/W1, 22-24.

Palestini, C., Basso, A., 2017. Geomatics as a survey tool to document and enhance the cultural and landscaped heritage of the monumental complexes in the mountains of Abruzzo, In: International Archives of the Photogrammetry, Remote Sensing and Spatial Information Sciences - ISPRS Archives, XLII-5/W1, 373-380.

Quattrini, R., Malinverni, E.S., Clini, P., Nespeca, R., Orlietti, E., 2015. From tls to HBIM. high quality semantically-aware $3 \mathrm{~d}$ modeling of complex architecture, In: International Archives of the Photogrammetry, Remote Sensing and Spatial Information Sciences - ISPRS Archives, XL-5/W4, 367-374.

Soler, F., Melero, F.J., Luzón, M.V., 2017. A complete 3D information system for Cultural Heritage documentation, Journal of Cultural Heritage, 23, 49-57. 